\title{
A Indexação da Revista Matéria
}

A visibilidade de uma revista científica depende em primeiro lugar da qualidade dos artigos que publica, mas atualmente, sobretudo, dos meios de indexação que usa. Isso porque são esses mecanismos de indexação que facilitam o acesso à revista dos pesquisadores de diferentes lugares, principalmente tratando-se de uma revista de publicação virtual. A introdução da revista Matéria na coleção SciELO foi muito importante para ampliar o seu espectro de atuação. Houve, desde então, uma atividade crescente de acesso aos seus artigos e também de submissão de novos artigos para publicação. Espera-se que uma aceitação idêntica por parte da comunidade científica da área de materiais ocorra a partir deste momento em que a revista Matéria acaba de ser aceita para indexarse na base Scopus (http://www.americalatina.elsevier.com/sul/ptbr/scopus.php). Esse representa um passo importante no sentido de progressivamente integrar mais a revista Matéria à área científica a qual está dedicada, publicando artigos de reputação, inovadores e em número crescente. Vale, entretanto, ressaltar que, além dos mecanismos de indexação aos quais está associado, outro fator preponderante para a garantia de visibilidade de uma revista científica é a citação dos artigos que publica. Se, de um lado, a inscrição em mecanismos diferentes de indexação é uma atividade dependente do trabalho da editoria da revista, de outro, a citação de artigos depende da atitude dos autores. Assim sendo, gostaria de solicitar aos autores que submetem seus artigos para publicação na revista Matéria que façam parte da sua revisão bibliográfica no acervo da própria revista, totalmente disponível de forma gratuita em meio digital, com os objetivos de beneficiar-se da informação especializada que este acervo oferece, mas também aumentar o índice de citação de artigos da revista.

Cordialmente,

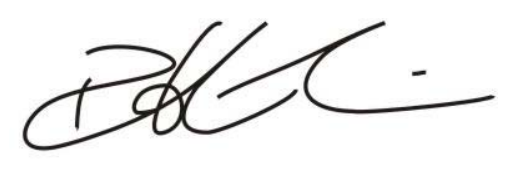

Paulo Emílio V. de Miranda

Editor-Chefe 